\title{
An epidemiological study of trauma and physical injuries among children admitted to government Hospitals
}

\author{
Avinash Thakur ${ }^{1}$, Murali Lalwani², Pavan Pandey ${ }^{3, *}$ \\ ${ }^{1}$ Resident Medical Officer, ${ }^{2}$ Professor, Dept. of Forensic Medicine and Toxicology, Gandhi Medical Officer, Bhopal, ${ }^{3}$ Program \\ Officer, Dept. of Family Planning, JHPIEGO, Chattisgarh, India
}

*Corresponding Author:

Email: dnameispaone@gmail.com

\begin{abstract}
Introduction: Reducing the preventable mortality and morbidity among children is one of the core indicators of sustainable development goals. This study was conducted with the objective of assessing the epidemiology, pattern, and outcome of physical injury and medico-legal case reports among pediatric population.

Materials and Methods: We conducted a cross-sectional study in the three districts of Madhya Pradesh. All children less than fifteen years of age brought with physical injuries to the nine selected public hospitals were included in the present studies. The data were analysed for gender, age group, mode \& type of injury.

Results: A total of 2,533 children under fifteen years of age were included in this study. Of the total children, medico-legal reports were filed for $368(14.5 \%)$ study participants and $82(3.23 \%)$ children died because of their injuries. Road traffic accidents (RTA) were the most common cause of physical injury closely followed by fall from height and recreational activities.

Conclusion: It is our firm conclusion that most cases of physical injuries among children could have been easily prevented. We identified several epidemiological factors which can be manipulated by various interventions to reduce the incidence of physical injuries among children.
\end{abstract}

Keywords: Child, Trauma, Injury, Medicolegal.

\section{Introduction}

Reducing the preventable child deaths was one of the most important health-related indicators among all millennium development goals. ${ }^{1}$ It is also one of the core indicators in the recently enshrined sustainable development goals. $^{2}$ Since the beginning of this millennium, there has been a substantial reduction in child mortality and morbidity due to infectious diseases. ${ }^{3}$ As the morbidity and mortality due to pre-, intra- and postnatal related causes is decreasing, the world has started focusing on other preventable causes of morbidity and mortality among children. ${ }^{4} \mathrm{~A}$ few developed countries have started giving more emphasis on preventing child morbidity due to non-convectional causes such as road traffic accident, domestic violence, parental abuse, recreation-related injuries etc. ${ }^{4}$

Accidents and other forms of harms are not only responsible for the deaths among children but are also a major reason for lifelong disability. ${ }^{4}$ According to an estimate near about 4-5 million children die from trauma-related injuries each year. ${ }^{5}$ In western countries like the United States of America, trauma is the leading cause of death among children..$^{5}$ Additionally, in the conflict-affected regions of the world, children are among the worst sufferers as they are completely or partially dependent on adults for their welfare. To make matter worse, there are paedophiles that prey on innocent children like vultures. Lastly, children often become victims of the various types of crimes such as abduction, trafficking, bonded labour and prostitution. ${ }^{6}$

India is not an exception when it comes to children being exposed to non-traditional causes of morbidity and mortality. Everynow and then we read reports of children being victims of road accidents, domestic violence, organized crimes and familial conflicts. In percentage terms, major crime heads under 'Crime Against Children' during 2016 were kidnapping \& abduction $(52.3 \%)$ and cases under the protection of children from sexual offences act, 2012 (34.4\%) including child rape. ${ }^{6} \mathrm{~A}$ maximum number of cases of crime against children were reported in Uttar Pradesh, Maharashtra and Madhya Pradesh, $(15.3 \%, 13.6 \%$ and $13.1 \%$ respectively). ${ }^{6}$ As per NCRB-2016 reports, in Madhya Pradesh alone there were a total of 6,496 reported crimes in which victims were children. ${ }^{6}$

Few studies have been conducted in India giving the detailed analysis of the epidemiology of the pediatrictrauma. ${ }^{7-9}$ However, no study has examined the medicolegal aspects of injuries among children. The injury among children can have multiple causes: domestic, accidental, recreational etc. Naturally, it becomes essential to study and identify the pattern of injuries in non-medicolegal and medicolegal cases. Thus, we conducted this study with the objective to study the medico-legal aspects and patterns of childhood injuries.

\section{Materials and Methods}

Study Design: This was a hospital-based crosssectional study.

Study Setting: The present study was conducted in the three districts of Madhya Pradesh.

Study Duration: The total duration of the study was twelve months (January-December 2017). The period 
of data collection was eight months (March-October 2017).

Source of Study Participants: Study participants for this study were recruited from government hospitals. Sampling Technique: We selected three district hospitals and 6 community health centres in the following way. We selected three district hospitals, one from each district. To select community health centres we employed two stage sampling technique. In the first stage, two blocks were selected from each district using simple random sampling technique. In the second stage, 1 community health centre was randomly selected from each pre-selected block.

Study Participants: All children of both genders under fifteen years of age were included in the study. Children coming to the selected hospitals with all kind of physical injury were included in our study.

Exclusion Criteria: (i) Children whose parents refused to give the consent for the study (ii) Children declared dead on their arrival at the hospital.

Outcome Variable: Any kind of physical injury for which a medico-legal report had to be filed.

Data Collection tool: To construct the questionnaire for the study, we conducted a systematic search on PubMed for the pre validated questionnaire and relevant studies carried out in past on similar topic. ${ }^{7-12}$ Thereafter a semi-structured interview questionnaire was constructed. The questionnaire was translated from English to native language (Hindi). The questionnaire was pre-tested on 30 children admitted to Hamidia Hospital, Bhopal and the results of pre-test were excluded from the study. The final version of study questionnaire had a reliability of $\alpha=0.95$. Detailed history taking and examination of all the study participants was conducted as per government's protocol by the medical officers posted in the respective hospitals. For each study participants, we collected detailed demographic information, gender, site of injury, mode of injury, place of injury, nature of the injury, any intervention required, and final outcome.

Data Collection: The parents or the guardian accompanying the child to the hospital were explained the purpose of the study, thereafter they were asked for consent. Before collecting data, the consent form was given (for literate) or read out (for illiterate) to participants and data was collected only after obtaining the written informed consent from the parents/guardian. Parents/guardians were also informed that they can withdraw their consent any time during the interview.

Data Collection: The data collectors were doctors/nurses/ANM posted in the health facility. All data collectors from all facilities of a selected hospital were simultaneously trained for data collection and conducting the interview.

Data Analysis: Descriptive analyses were done to study the distribution of dependent variables among study participants. The present study was approved by the ethical committee board on human research.

\section{Results}

During the period of data collection, a total of 3,284 children came to the selected hospitals with any kind of injury. Of these, 579 had to be referred out to the higher/other medical centres and parents of 172 children refused to give consent for the study. Thus, only 2,533 children were included in the final data analysis. Of the total children brought with the physical injury, medico-legal reports were filed for 368 (14.5\%) study participants and $82(3.23 \%)$ participants died because of their injuries. In our study, most of the injuries are inflicted outside their respective homes.

Table 1 details the distribution of study participation by their age, gender, and mode of injury. The mean age of study participants was 8.9 years. Most common cause of injury was road traffic accidents, followed by fall from height $(21.6 \%)$, and closely followed by sports /recreational $(21.0 \%)$ while sexual assault $(1.5 \%)$ was the least common mode of acquiring an injury. We observed that both boys and girls were the victims of sexual assault. Table 2 illustrates in greater details about the mode of injury, while table 3 reflects the mortality related to various kinds of injury.

Table 1: Distribution of study participants by demographic variables modes and type of injuries $(\mathrm{n}=\mathbf{2 , 5 3 3 )}$

\begin{tabular}{|c|c|c|}
\hline Study variable & Physical injury $\mathrm{n}(\%)$ & Medico-legal case $n=368(\%)$ \\
\hline \multicolumn{3}{|c|}{ Age (in years) } \\
\hline$\leq 2$ & $323(12.8)$ & 0 \\
\hline $2-\leq 5$ & $528(20.8)$ & $112(30.4)$ \\
\hline $6-\leq 10$ & $815(32.2)$ & $117(31.8)$ \\
\hline $11-15$ & $867(34.2)$ & $139(37.8)$ \\
\hline \multicolumn{3}{|l|}{ Gender } \\
\hline Male & $1374(54.2)$ & $195(53.0)$ \\
\hline Female & $1159(45.8)$ & $173(47.0)$ \\
\hline \multicolumn{3}{|l|}{ Mode of injury } \\
\hline Fall from height & $547(21.6)$ & $12(3.3)$ \\
\hline Burn & $398(15.7)$ & $6(1.6)$ \\
\hline RTA-occupant & $446(17.6)$ & $25(6.8)$ \\
\hline
\end{tabular}




\begin{tabular}{|l|c|c|}
\hline RTA-non-occupant & $283(11.2)$ & $112(30.4)$ \\
\hline Physical Assault & $136(5.4)$ & $136(37.0)$ \\
\hline Sexual assault & $38(1.5)$ & $38(10.3)$ \\
\hline Poisoning & $152(6.0)$ & $39(10.6)$ \\
\hline Sports/recreational & $533(21.0)$ & 0 \\
\hline
\end{tabular}

Table 2: Distribution of participants by injury characteristics due to falling, road traffic accident, burn and poisoning

\begin{tabular}{|c|c|c|}
\hline Study variable & Physical injury $\mathrm{n}(\%)$ & Medico-legal case $n(\%)$ \\
\hline \multicolumn{3}{|l|}{ Fall from height $(n=547)$} \\
\hline Roof/Balcony & $122(22.3)$ & $2(16.7)$ \\
\hline Tree & 157(28.7) & 0 \\
\hline Stairs & 132(24.1) & $1(8.3)$ \\
\hline Bed/chair/sofa & $97(17.7)$ & 0 \\
\hline Fall into well/pit & $39(7.1)$ & $9(75.0)$ \\
\hline \multicolumn{3}{|c|}{ Road Traffic Accident- Occupant $(n=406)$} \\
\hline Bicycle & $248(61.1)$ & 0 \\
\hline Two-wheeler & $112(27.6)$ & 0 \\
\hline Four Wheeler & $46(11.3)$ & 0 \\
\hline \multicolumn{3}{|c|}{ Road Traffic Accident Non-occupant (n=283) } \\
\hline Bicycle & $26(9.2)$ & 19(76.0) \\
\hline Two-wheeler & 167(59.0) & $6(24.0)$ \\
\hline Four Wheeler & $86(30.4)$ & 0 \\
\hline Train & $4(1.0)$ & 0 \\
\hline \multicolumn{3}{|l|}{ Burn $(n=398)$} \\
\hline Electric & $29(7.3)$ & $1(16.7)$ \\
\hline Scald (Hot liquid) & $162(40.7)$ & $3(50.0)$ \\
\hline Cracker & $119(29.9)$ & 0 \\
\hline Flame/contact burns & $88(22.1)$ & $2(33.3)$ \\
\hline \multicolumn{3}{|l|}{ Poisoning(n=152) } \\
\hline Accidental & 113(74.3) & $10(25.6)$ \\
\hline Suicidal & 11(7.2) & $9(23.1)$ \\
\hline Homicidal & $28(18.4)$ & $20(51.3)$ \\
\hline \multicolumn{3}{|l|}{ Type of poison $(n=152)$} \\
\hline Agricultural Insecticide & $37(24.3)$ & $14(35.9)$ \\
\hline Kerosene & $7(4.6)$ & 0 \\
\hline Medications/Drugs & $58(38.2)$ & $17(43.6)$ \\
\hline Domestic Insecticide & $34(22.3)$ & $8(20.5)$ \\
\hline Natural & $16(10.5)$ & 0 \\
\hline
\end{tabular}

Table 3: Distribution of fatal injury among study participants $(\mathbf{n}=\mathbf{8 2})$

\begin{tabular}{|l|c|c|}
\hline \multirow{2}{*}{ Study variable } & \multicolumn{2}{|c|}{ Death } \\
\cline { 2 - 3 } & n & \% \\
\hline Fall from height & 27 & 32.9 \\
\hline RTA & 28 & 34.1 \\
\hline Burn & 7 & 8.5 \\
\hline Physical assault & 4 & 4.9 \\
\hline Sexual assault & 0 & - \\
\hline Poisoning & 21 & 25.6 \\
\hline
\end{tabular}

\section{Discussion}

Non-convectional causes of morbidities are swiftly becoming a significant cause of childhood mortality and disability. ${ }^{14,15}$ Trauma resulting from an array of agents among the pediatric population is on the rise and are also becoming important social problems. ${ }^{16,17}$ In comparison to infectious diseases recovery from physical injuries may be more painful, long and costlier. ${ }^{18}$ Additionally, many children who survive are at risk of developing a permanent disability, requiring lifelong care and have a significant impact on their psychosocial health and financial independence. ${ }^{19}$ In our study, we observed that boys outnumbered girls in sustaining physical injuries. Similar observations were also reported other studies. ${ }^{7-9}$ In our opinion, there can be several explanations for such observation; boys enjoy more freedom, opportunities, and facilities as compared to girls in Indian society. Therefore; boys are more exposed to risk factors located both outdoor as well as indoor. 
In our study, we observed that the most common cause of injury was road traffic accidents, followed by fall from height (21.6\%), and closely followed by sports /recreational activities (21.0\%). Similar to our study Sharma et al., also noted that $52.61 \%$ of their study participants had sustained injury secondary to RTA followed by falls related injuries $(36.32 \%) .^{7}$ Further, we noted that RTA was much more common among boys in comparison to than girls. Among those sustaining injuries from RTA, a higher proportion of children were occupants of any kind of vehicle. We noted that most of the fall related injuries (fall from the roof) coincided with the kite flying festival season in the districts included in the present study. We noted that fractures of limb and concussions were most commonly observed injury among victims of both RTA and fall from height. Similar to our observations, a study conducted by Hyder et al. in African continent have reported that about one-third of all injuries among children were due to falls. ${ }^{10} \mathrm{~A}$ similar study in Nepal reported that falls were reported as the most common injury, occurring in $65 \%$ of study participation. ${ }^{11}$ It is our opinion that such high rate of falls from 'roof' occurs secondary to both the lack of an adult supervision while playing on the roof and lack of safety measures. In our study, fall from bed was seen most commonly among children $<2$ years which is consistent with other studies.

We also noted that most cases of burns were caused due to hot liquids coming in contact with child's skin (scald) followed by burns due to crackers. Contrary to our study, Sharma et al., noted that flame burns were the most common forms of burns. ${ }^{7}$ However, similar to our study, Ahmad and Parbhoo in their study noted that hot liquids were more common cause of burn injuries as compared to flame burns. ${ }^{12}$ In our study, the mortality rate among victims of physical injury was 3. 3.23\%. Many other studies such as Sharma et al., Ameh and Mshelbwala reported slightly higher mortality rates. ${ }^{13}$ Such low levels of mortality in our study could be due to the fact that we excluded children who were declared dead on their arrival to the hospital.

Conclusion and Recommendations: At present most of the government's programmes are directed at preventing infectious diseases and birth-related complications. $^{20,21}$ The government has yet to enact or sanction a program directed at prevent injuries among pediatric population. In conclusion, we would like to state that most of the injuries could have been prevented in the first place. Most of the factors predisposing to pediatric trauma could have been modified by different kinds of intervention. ${ }^{14}$ It is our firm opinion that the high incidence of injuries among children could have been avoided if children were kept under an adult supervision while playing and other recreational activities. Parents, guardians and other caretakers should be counselled regarding supervision during activities involving seen and unseen harm.

\section{References}

1. Akiyama S. Millenium development goals. New Approaches to Development and Changing Sector Issues. 2005;34.

2. Griggs D, Stafford-Smith M, Gaffney O, Rockström J, Öhman MC, Shyamsundar P, Steffen W, Glaser G, Kanie N, Noble I. Policy: Sustainable development goals for people and planet. Nature. 2013 Mar 20;495(7441):305.

3. Nath A. India's progress toward achieving the millennium development goals. Indian journal of community medicine: official publication of Indian Association of Preventive \& Social Medicine. 2011 Apr;36(2):85.

4. WHO/UNICEF. Child and Adolescent Injury Prevention: A Global Call to Action. Geneva, Switzerland: WHO; 2005. Available from: http://apps.who.int/iris/bitstream/10665/43279/1/9241593 415_eng.pdf

5. Holder Y, Peden M, Krug E, Lund J, Gururaj G, Kobusingye O. Injury Surveillance Guidelines. Geneva: World Health Organization; 2001. Available from: http://www.who.int/ violence_injury_prevention/media/en/136.pdf.

6. National Crime Records Bureau. Crime in India 2016.

7. Sharma M, Lahoti BK, Khandelwal G, Mathur RK, Sharma SS, Laddha A. Epidemiological trends of pediatric trauma: A single-center study of 791 patients. $J$ Indian Assoc Pediatr Surg 2011;16:88-92.

8. Verma S, Lal N, Lodha R, Murmu L. Childhood trauma profile at a tertiary care hospital in India. Indian Pediatr 2009;46:168-71.

9. Kundal VK, Debnath PR, Sen A. Epidemiology of pediatric trauma and its pattern in urban India: A tertiary care hospital-based experience. J Indian Assoc Pediatr Surg 2017;22:33-7.

10. Hyder AA, Sugerman D, Ameratunga S, Callaghan JA. Falls among children in the developing world: A gap in child health burden estimations? Acta Paediatr 2007;96:1394-8.

11. Poudel-Tandukar K, Nakahara S, Ichikawa M, Poudel $\mathrm{KC}$, Joshi AB, Wakai S. Unintentional injuries among school adolescents in Kathmandu, Nepal: A descriptive study. Public Health 2006;120:641-9.

12. Ahmad M. Pakistani experience of childhood burns in a private setup. Ann Burns Fire Disasters 2010;23:25-7.

13. Ameh EA, Mshelbwala PM. Challenges of managing paediatric abdominal trauma in a Nigerian setting. Eur $J$ Pediatr Surg 2007;2:90-5.

14. Hatamabadi HR, Mahfoozpour S, Alimohammadi H, Younesian S. Evaluation of factors influencing knowledge and attitudes of mothers with preschool children regarding their adoption of preventive measures for home injuries referred toacademic emergency centres, Tehran, Iran. Int J Inj Contr Saf Promot 2014;21:252-9.

15. Hatamabadi H, Mahfoozpour S, Forouzanfar M, Khazaei A, Yousefian S, Younesian S. Evaluation of parameter related to preventative measures on the child injuries at home. J Saf Promot Inj Prev 2013;1:140-9.

16. Molcho M, Walsh S, Donnelly P, Matos MG, Pickett W. Trend in injury-related mortality and morbidity among adolescents across 30 countries from 2002 to 2010. Eur J Public Health 2015;25 Suppl 2:33-6.

17. Peden M, Oyegbite K, Ozanne-Smith J, Hyder AA, Christine B, Rahman AK, et al. World Report on Child Injury Prevention. Geneva: World Health Organization; 2009. Available from: https://www.unicef.org/eapro/World_report.pdf.

18. Bangdiwala SI, Anzola-Pérez E, Romer CC, Schmidt B, Valdez-Lazo F, Toro J, et al. The incidence of injuries in 
young people: I. Methodology and results of a collaborative study in Brazil, Chile, Cuba and Venezuela. Int J Epidemiol 1990;19:115-24.

19. Karbakhsh M, Zargar M, Zarei MR, Khaji A. Childhood injuries in Tehran: A review of 1281 cases. Turk $J$ Pediatr 2008;50:317-25.

20. Integrated Child Development Scheme. Ministry of Women and Child Development, Government of India

21. National Health Mission, Ministry of Health and Family Welfare, Government of India. 